\title{
LITERATURA INDÍGENA EM DEBATE: SUPERANDO O APAGAMENTO POR MEIO DO LETRAMENTO LITERÁRIO
}

Marisa Martins Gama-Khalil (UFU) Lorena Faria de Souza (UFU)

Resumo: Este trabalho visa refletir sobre as contribuições da literatura indígena no letramento literário de crianças para a formação de uma identidade leitora multiétnica e multicultural. Apresentamos essa literatura como parte do processo de resistência em busca do (re) conhecimento da identidade e alteridade dos indígenas, e procuramos analisar como se dá a presença (ou ausência) da temática na escola e nos Parâmetros Curriculares Nacionais, considerando a perspectiva do documento em relação ao ensino de literatura. Por fim, discutimos questões sobre a produção e recepção da temática étnico-racial na literatura infantil e juvenil, reforçando a crença de que o letramento literário realizado com a representação da diversidade de vozes contribui significativamente para a humanização e o exercício da cidadania.

Palavras-chave: Literatura Indígena, Letramento literário, Resistência.

Abstract: This paper aims to reflect on the contributions of indigenous literature in literary literacy of children to form an identity reader multiethnic and multicultural. We present this literature as part of the search for resistance process of acknowledgment of the identity and otherness of the indigenous, and tried to analyze how is the presence (or absence) of the thematic in school and the Parâmetros Curriculares Nacionais, considering the perspective of document in relation to the teaching of literature. Finally, we discussed issues on the production and reception of ethnic-racial thematic in child and youth literature, reinforcing the belief that the literary literacy performed with the representation of the diversity of voices contributes significantly to the humanization and for the exercise of citizenship.

Keywords: Indigenous Literature, Literary literacy, Resistance. 


\section{PROLEGÔMENOS...}

Cerca de vinte anos antes da publicação da Declaração das Nações Unidas sobre os Direitos dos Povos Indígenas em 2008, o crítico literário Antonio Candido discutia a questão dos direitos humanos, estabelecendo uma relação entre estes e a literatura. À época, mais precisamente em 1988, Candido apontava uma contradição, ainda presente em nossos tempos, entre o progresso e a irracionalidade. Para o autor, o máximo de racionalidade técnica e domínio sobre a natureza poderiam levar ao desenvolvimento de soluções para os problemas materiais do homem, no entanto, o que se via era o aumento da barbárie, ao excluir do progresso grandes contingentes de pessoas que ainda viviam na miséria. Associando essa discussão à questão dos povos indígenas, Graça Graúna (2013) afirma que "o chamado 'progresso' agride, fragmenta, desloca traçando caminhos contrários aos sonhos das sociedades indígenas" (GRAÚNA, 2013, p.25). As demarcações históricas de fronteiras advindas dos "novos tempos" retiraram os povos indígenas de suas terras, provocando uma incessante busca desses indivíduos por seu "lugar no mundo". Ainda sobre esse aspecto, Cardoso (2011) afirma:

As fronteiras do mundo capitalista e globalizado do século XXI criaram um 
paradoxo. Ao mesmo tempo em que as fronteiras diminuem, aumenta mais a distância entre os povos, pois os choques culturais provocam sempre a opressão daquele que é considerado inferior. No caso dos índios, temos toda uma realidade caracterizada por séculos de dominação do branco, ocorrendo assim o extermínio, bem como a usurpação de sua cultura e identidade. Vivemos uma época caracterizada pelo interculturalismo, mas isso não significa que estejamos abertos a aceitar o que é "diferente". Ao mesmo tempo em que os povos procuram externar suas identidades, cresce o preconceito daqueles que não aceitam a mudança do status quo de dominação (CARDOSO, 2011, p.9).

Mesmo diante de tais adversidades, convém retomar as ideias de Candido, ao lembrar que esse autor conseguiu observar perspectivas positivas em suas reflexões sobre os direitos humanos, afirmando que a barbárie, ao menos, não é mais elogiada, numa nova atitude que pode advir de um sentimento de culpa ou até mesmo por medo das vozes dos grupos que sempre se tentou silenciar, "porque a sociedade sentiu que eles podem ser um fator de rompimento do estado de coisas, e o temor é um dos caminhos para a compreensão" (CANDIDO, 2004, p.170). O crítico demonstra ainda uma percepção na mudança do discurso político, ao mencionar que este parece revelar o constrangimento diante 
da injustiça social, e que a insensibilidade dos dirigentes tem sido pelo menos disfarçada, já que o sofrimento não deixa tão indiferente a média da opinião.

Se ventos positivos puderam ser sentidos quando Candido percebeu no cerne da questão dos direitos humanos, a manifestação consciente de que a desigualdade é insuportável e que o semelhante precisa ser incluído no mesmo elenco de bens que reivindicamos, nos tempos atuais podemos afirmar que esses ventos continuam a soprar, ainda que lentamente. Após a promulgação da Constituição Federativa Brasileira de 1988, exemplos desses bons ventos puderam ser sentidos na publicação de diversos documentos oficiais que buscaram estabelecer padrões igualitários no tratamento das minorias, especialmente relacionados à educação. Dentre eles, numa ordem cronológica, podem ser citados: a Lei de Diretrizes e Bases da Educação Nacional - LDB, promulgada em 1996; os Parâmetros Curriculares Nacionais - PCNs, publicados em 1997 e 1998; e particularmente o Referencial Curricular Nacional para as Escolas Indígenas (RCNEI), lançado pelo MEC em 1998. Cerca de 10 anos depois, em 2007, temos a publicação dos Cadernos da Secretaria de Educação Continuada, Alfabetização e Diversidade (SECAD), cujo terceiro número versa sobre a Educação Escolar Indígena. 
Nesse ínterim, modificações na LDB foram realizadas pela Lei 10.639/03, que trata da inserção obrigatória do ensino da História e Cultura Afro-brasileira em todos os anos de ensino e, mais recentemente, pela Lei 11.645/08, que inclui, ainda, a temática indígena em todo o currículo escolar, especialmente nas áreas de educação artística, literatura e história brasileira. Também em 2008, a ONU proclamou a Declaração dos Direitos dos Povos Indígenas, reconhecendo a necessidade urgente de respeitar e promover os direitos intrínsecos dos povos indígenas.

Ora, estabelecendo um contraponto com o ano de 1500 , em que os europeus aqui chegaram, podemos nos perguntar: a promulgação de tantos documentos e leis foi realmente necessária para que o respeito aos direitos dos povos indígenas fosse declarado, cerca de 500 anos após o primeiro episódio de resistência desses povos, ao demonstrar desconfiança diante dos estranhos que aqui atracaram suas embarcações? Mesmo diante de uma vasta documentação legal, as escolas brasileiras estão preparadas de fato para lidar com as especificidades da cultura indígena, respeitando seus direitos? Como tem sido a participação da literatura nesse processo, em especial da infantojuvenil, como representação da identidade e da alteridade dos 
povos indígenas? Este artigo pretende incitar a discussão sobre esses e outros questionamentos, sem a pretensão de promover uma análise exaustiva do tema, haja vista o crescente número de trabalhos que versam sobre a temática, particularmente nas áreas da Antropologia, História e Letras.

Para tanto, defendemos que a literatura é uma potencial forma de resistência, pois é fato que a arte literária instiga os leitores à revisão de posicionamentos, na medida em que reverbera as perguntas que se fazem necessárias no seu tempo. Beatriz Sarlo (2005, p.30), ao dissertar sobre essa questão, defende que o escritor de literatura "não procura respostas e sim perguntas: indaga sobre aquilo que, numa época, parece, além de todo princípio de compreensão, a resistência que o horrível, o sinistro, o sublime ou o trágico opõem a outras formas do discurso e da razão". Se oferecesse respostas aos seus leitores, ao invés de fomentar perguntas, a literatura agiria no sentido de fixação de saberes; contudo, ela é o contrário disso, ela faz os saberes girarem, propiciando sua circulação para que eles possam ser observados a partir de outros prismas e, assim, possam ser redimensionados. Por isso, a literatura é a única forma de linguagem que pode ser capaz de fugir ao gregarismo da língua, permitindo, como ensina Roland Barthes (2007, 
p.16), "ouvir a língua fora do poder, no esplendor de uma revolução permanente de linguagem". Entendemos, nesse sentido, que a literatura pode possibilitar um contato com a temática indígena de forma mais revolucionária, permitindo o deslocamento dessa temática da margem para o centro e, com isso, instigando possivelmente novas posturas dos leitores. Procuraremos, ainda, analisar como (ou se) a temática indígena tem sido adotada nas escolas e nos documentos oficiais e, também, pretendemos discutir o contexto da produção e recepção das temáticas étnicoraciais nas literaturas infantil e juvenil, por acreditarmos no letramento literário como fonte de humanização dos sujeitos e forma de ressignificar práticas sociais.

\section{LITERATURA COMO FORMA DE RESISTÊNCIA INDÍGENA: UMA BUSCA INCESSANTE POR SEU LUGAR NO MUNDO}

As palavras que iniciam esta seção, inspiradas nos escritos de Graça Graúna (2013), revelam a constante tentativa dos povos indígenas, após tantos processos de exclusão, de ter a demarcação e posse de suas terras e o reconhecimento das especificidades de sua cultura ao longo do tempo na busca por "um lugar no mundo". O historiador Porto Borges (2005) relaciona as lutas indígenas à expansão capitalista, e afirma que essa busca incessante, como forma de resistência, 
manifestou-se de diversas formas, que variavam de acordo com os desafios impostos:

Historicamente os povos indígenas sempre reagiram à violação e à conquista de seus territórios tradicionais; e estas respostas variavam de acordo com o desafio imposto pelos distintos momentos da expansão capitalista, inicialmente europeia e, mais tarde, condicionada à formação econômica brasileira. [...] A resistência destes grupos era determinada tanto pela especificidade da frente de expansão quanto pela lógica cultural do povo que a sustentava. (BORGES, 2005, p.42-43).

Funari e Piñon (2014) também discutem a resistência indígena do ponto de vista histórico, associando-a aos movimentos políticos e econômicos pelos quais o Brasil passou desde o contato com os europeus. No entanto, os autores apresentam uma reação indígena mais sistemática apenas no final do século XX, especialmente a partir da Anistia em 1979 e do retorno dos civis ao poder em 1985. Antes disso, contudo, no início dos anos 1970, já havia manifestações do movimento indígena na política e na literatura. Mesmo com tais manifestações, foi após o painel da chamada "política etnocida", ocorrido em meados da década de 1980, que campanhas contra as invasões de território ganharam corpo, e as discussões em torno da elaboração da Constituição 
de 1988 se intensificaram. De fato, após a promulgação da Constituição Brasileira de 1988 os índios passaram a ser reconhecidos legalmente em seus direitos, conforme 0 artigo 231: "São reconhecidos aos índios sua organização social, costumes, línguas, crenças e tradições, e os direitos originários sobre as terras que tradicionalmente ocupam, competindo à união demarcá-las, proteger e fazer respeitar todos os seus bens". Tal fato promoveu um avanço do movimento indígena, com o surgimento de representações de bases diversas organizadas em numerosas associações.

A literatura surge nesse cenário como uma forma de resistência que vem testemunhar a vivência indígena e valorizar a memória e a alteridade desses povos, em meio a um intenso processo de transculturação que reúne num amálgama a literatura indígena e a sociedade na qual ela se insere. Graúna (2013) considera a literatura indígena contemporânea como um lugar utópico de sobrevivência, numa confluência de vozes silenciadas. Nesse sentido, as palavras da autora vêm dizer:

Nesse processo de reflexão, a voz do texto mostra que os direitos dos povos indígenas de expressar seu amor à terra, de viver seus costumes, sua organização social, suas línguas e de manifestar suas crenças nunca foram considerados de fato. Mas, apesar da intromissão dos 
valores dominantes, o jeito de ser e de viver dos povos indígenas vence o tempo: a tradição literária (oral, escrita, individual, coletiva, híbrida, plural) é uma prova dessa resistência. (GRAÚNA, 2013, p.15).

Sobre essa literatura, Capriles (Apud GRAÚNA, 2013, p.20) afirma que "foi sistematicamente negada até bem avançado o século XX", permanecendo às margens da tradição literária. Apesar da negação, autores e autoras indígenas têm preservado suas origens por meio da percepção de que a literatura é uma das formas de representar a memória, a auto-história e a alteridade de seus povos. Por meio da escrita de suas tradições orais, os indígenas conseguem atingir leitores que dantes desconheciam sua cultura ou a conheciam apenas sob a ótica historicizada branca. A respeito dessa ótica, cabe mencionar como a figura do índio geralmente foi tratada na literatura do passado, e em parte ainda no presente, numa perspectiva idealizada. Associando essa questão ao contexto das literaturas infantil e juvenil, Lajolo e Zilberman (1993) comentam a entrada do índio como personagem no cenário da literatura infantil no início do século $X X$, afirmando que, na grande maioria das vezes, os personagens brancos são representados como heróis, e "o índio, porém, está sempre do lado errado, a não ser 
quando se civiliza, convertendo-se ao cristianismo e aliandose aos brancos" (LAJOLO; ZILBERMAN, 1993, p.131). Ora, essa visão do índio que se converte e alia-se aos brancos é uma constante em boa parte da nossa literatura. Já na Carta de Pero Vaz de Caminha fala-se sobre a "inocência e docilidade" de nossos índios, a quem poderia imprimir-se facilmente qualquer cunho que the quisessem dar, especialmente o cunho cristão. Na Carta, os índios são dóceis, inocentes, seres que habitam um paraíso. Essa falaciosa inocência do índio e a ausência de uma vinculação deste com instituições como o Estado e a religião, por exemplo, é que deram origem, alguns séculos mais tarde, ao mito do bom selvagem de Jean-Jacques Rousseau.

Obviamente, temos que ressaltar que a Carta não se configura como um texto literário propriamente dito, e é por esse motivo que ela se insere, na historiografia literária, no âmbito da literatura de viagem, compreendendo-se, nesse caso, a palavra literatura concernente ao seu significado geral: conjunto de textos escritos (como é o caso da literatura jurídica e da médica, por exemplo). Mas o texto da Carta figura erroneamente na historiografia literária para suprir a ausência de uma literatura naquele período no Brasil.

Todavia, foi justamente esse caráter idealizado atrelado aos índios que se tornou a base da literatura indigenista de 
cunho romântico, escrita principalmente por Gonçalves Dias, Gonçalves de Magalhães e José de Alencar, em cujas obras são retratados índios repletos de características idealizadas, como bravura, coragem, fidelidade e dedicação às tradições (mas também ao homem branco), na busca de uma figura que representasse a identidade nacional do povo brasileiro e numa falsa valorização de nossas origens.

Antonio Candido trata da questão e diz que os românticos "civilizaram" a figura do índio, injetando-lhe os padrões do cavalheirismo convencional, enquanto os modernistas procuraram no índio e no negro o primitivismo, "que injetaram nos padrões da civilização dominante como renovação e quebra das convenções acadêmicas" (CANDIDO, 1999, p.70). É fato que muitos autores modernistas buscaram desconstruir paradigmas de cunho eurocêntrico em relação ao índio, buscando uma revisão das representações literárias canônicas, mas as literaturas infantil e juvenil em geral não compartilharam desse propósito. Vale destacar que alguns autores, como Joel Rufino dos Santos, conseguiram ficcionalizar a imagem do índio sem estereotipá-lo ou idealizálo. Entretanto, temos, de modo geral, os índios representados na literatura seguindo uma visão estereotipada, contribuindo para a valorização do herói branco, numa perspectiva marcada 
pela visão eurocêntrica. O resultado disso é a representação da voz do índio subordinada à voz do branco. Não há, até o final do século XX, obras literárias infantis e juvenis assinadas por autores indígenas, até porque a literatura produzida por índios muitas vezes foi (ou ainda é) escrita em sua língua nativa e, quando isso acontece, o público-alvo é reduzido, demonstrando a carência dessas produções em Língua Portuguesa até alguns anos atrás (THIÉL, 2014).

Assim, ao abordar a autoria de obras literárias, destinadas aos públicos infantil e juvenil, feitas por índios antes do final do século $X X$, podemos falar não apenas em uma marginalização, e sim, num quase total apagamento. No entanto, mesmo diante de todos os processos de exclusão, se pensarmos na questão hoje, veremos como a resistência do movimento indígena se configurou na literatura, na qual "podemos considerar a existência de uma produção diferenciada, voltada ao público infantil e juvenil, cuja voz autoral pretende assumir a construção da identidade indígena" (MARTHA, 2012, p.328). Sobre esse aspecto, Boudreau (1993) afirma que o amor à terra dos ameríndios alimenta esses autores e autoras na configuração de um espaço de denúncia, no qual buscam expressar não só sua identidade, mas sua alteridade por meio da literatura, que 
implica uma forma de sobrevivência para as nações indígenas e de resistência para os "brancos".

$\mathrm{Na}$ configuração da literatura indígena contemporânea brasileira, nomes de autores e autoras como os de Daniel Munduruku, Graça Graúna, Eliane Potiguara e Kaká Werá Jecupé caminham para compor uma tradição literária, numa luta pelo reconhecimento das especificidades de sua cultura:

Os aspectos intensificadores da literatura indígena contemporânea no Brasil remetem à auto-história de resistência, [...] à esperança de um outro mundo possível, com respeito às diferenças. O reconhecimento desses aspectos perpassa na contribuição de escritores(as), pesquisadores(as) e artistas que se empenham em transmitir e "traduzir" com apurada sensibilidade a poética de tradição oral dos povos indígenas no Brasil e na Ameríndia. (GRAÚNA, 2013, p.64).

No entanto, essa contribuição não terá sentido se não tiver reverberações sociais. E aqui entra o papel da escola como locus privilegiado de interação social e "elemento capital na conformação das imagens a respeito dos indígenas" (FUNARI; PIÑON, 2014, p.115). Diante disso, cabe discutir como tem sido feito o ensino de literatura nas instituições escolares, considerando ainda a perspectiva dos Parâmetros Curriculares Nacionais do conteúdo de 
Língua Portuguesa sobre esse ensino e a temática indígena, caso haja a presença desta no documento.

\section{A PRESENÇA (OU AUSÊNCIA) DA TEMÁTICA INDÍGENA NA ESCOLA E NOS PCNS LÍNGUA PORTUGUESA: COMO TEM SIDO FEITO O ENSINO DE LITERATURA?}

Ao fazer uma perspectiva histórica a respeito da chegada da escola ocidental ao Brasil, é impossível negar que tal instituição tenha servido como instrumento de opressão do sujeito dominante às culturas indígenas. Sob a égide da civilização, os colonizadores europeus transfiguraram etnicamente nossas origens, "pela desindianização forçada dos índios" (RIBEIRO, 1995, p.13). Do projeto jesuíta aos tempos de República, muitos foram os processos de exclusão dos indígenas, seja por tentativas de aculturação ou de apagamento - tentativas porque, na percepção indígena, não se pode negar a existência da cultura de alguém, mesmo que se tenha tido contato com o outro: o índio não deixa de ser ele mesmo. A escola teve papel fundamental nesse processo, pois, como mencionamos, muito contribuiu e influenciou na formação das imagens que se tinha (e ainda se tem) sobre os indígenas, condicionadas à perspectiva do branco. Sobre tal aspecto, Funari e Piñon (2014) dizem:

a escola foi importante, tornando historicamente significativo o fato de 
ter, por muito tempo, excluído a figura do índio da representação do país, da sua língua, história e ambiente, quando não o apresentou, de forma oblíqua, como atraso bárbaro a ser superado. Quando, finalmente, a figura do índio foi incorporada, manteve em grande parte o caráter exótico e externo à sociedade brasileira, tomada por uma unidade relativamente homogênea. Apenas nos últimos anos é que houve a inclusão da pluralidade como um valor positivo e o consequente reconhecimento dos indígenas como parte importante da nossa sociedade e sua cultura como significativa na conformação da nacionalidade brasileira. Entretanto, esse processo não deixa de apresentar contradições, com políticas escolares que a um só tempo defendem a pluralidade e mantêm esquemas de classificação que excluem o índio da sociedade brasileira. (FUNARI e PIÑON, 2014, p.115).

Quando os autores mencionam a inclusão da pluralidade como valor positivo e a adoção de políticas escolares que defendem essa ideia nos últimos anos, podemos pensar na publicação dos Parâmetros Curriculares Nacionais, em 1997 e 1998, para orientar o ensino nos níveis Fundamental I e II, como um exemplo que propôs mudanças nas práticas escolares desenvolvidas até então. Na apresentação do documento, comum a todas as áreas, menciona-se que sua elaboração procurou respeitar a pluralidade ao mesmo 
tempo em que considerava necessária a definição de referências nacionais para o ensino:

Os Parâmetros Curriculares Nacionais foram elaborados procurando, de um lado, respeitar diversidades regionais, culturais, políticas existentes no país e, de outro, considerar a necessidade de construir referências nacionais comuns ao processo educativo em todas as regiões brasileiras. (BRASIL, 1998, p. 5).

O documento também menciona os objetivos do Ensino Fundamental, relacionados, dentre outros aspectos, à compreensão do valor da cidadania e ao posicionamento crítico frente a diferentes contextos sociais e ao meio ambiente. Dessesobjetivos, dois nos parecem particularmente pertinentes à discussão do presente trabalho:

(1) conhecer características fundamentais do Brasil nas dimensões sociais, materiais e culturais como meio para construir progressivamente a noção de identidade nacional e pessoal e o sentimento de pertinência ao país;

(2) conhecer e valorizar a pluralidade do patrimônio sociocultural brasileiro, bem como aspectos socioculturais de outros povos e nações, posicionando-se contra qualquer discriminação baseada em diferenças culturais, de classe social, de crenças, de sexo, de etnia ou outras características individuais e sociais (BRASIL, 1998, p.7). 
Especificamente no caso dos PCNs Língua Portuguesa, esses dois importantes objetivos não se traduziram em sugestões de propostas de ensino, mostrando que as temáticas étnico-raciais não estão devidamente abordadas no documento. Tal afirmação pauta-se ainda na inobservância, em todas as 106 páginas dos referidos PCNs, de termos como "étnico", "índio", "indígena”, "negro" ou "afrodescendente". Além disso, o próprio termo "pluralidade" é citado apenas duas vezes: a primeira no objetivo mencionado acima e a segunda ao citarem a expressão "pluralidade cultural" como tema transversal.

Sendo assim, as principais mudanças observadas para o ensino de Língua Portuguesa referem-se principalmente à nova concepção de linguagem adotada, que passa a valorizar a voz do discente em sala de aula e considerar a língua em funcionamento, no lugar da simples decodificação e excessiva valorização das regras da gramática normativa. Nesse sentido, os PCNs sugerem que a língua "é um sistema de signos específico, histórico e social, que possibilita a homens e mulheres significar o mundo e a sociedade" (BRASIL, 1998, p.20), numa perspectiva pragmática da natureza da linguagem que tem em vista o processo de interlocução realizado nas diferentes práticas sociais, em diferentes situações comunicativas. 
A linguagem, capaz de levar o indivíduo a inserir-se socialmente, sob esse ponto de vista pragmático, pode levar ao desenvolvimento da competência discursiva em relação aos textos informativos, mas do ponto de vista do texto literário, outros aspectos se fazem importantes. Considerando o tratamento dos $\mathrm{PCNs}$ a respeito desses textos, veremos que a discussão feita no documento deixa muito a desejar, pois não se debruça a tratar especificamente a promoção do letramento literário, limitando-se apenas a citar que o texto literário possui singularidades, além do fato de que este texto não pode ser tomado como pretexto para o tratamento de questões outras que não contribuem para a formação de leitores familiarizados com as sutilezas das construções literárias.

Da perspectiva do letramento literário, o caráter pragmático de abordagem dos gêneros não é capaz de contemplar a necessidade de fruição estética e humanização pertinente à obra literária. Regina Zilberman (2007) discute a questão e toma como referência os PCNs, por estes "representarem uma tendência no âmbito do ensino" (p.259). A respeito dos objetivos do documento, especificamente em relação ao ensino de Língua Portuguesa, a autora diz que remontam à Retórica e sua tradição, por lidarem com o uso 
público da linguagem, num processo em que a literatura aparece enquanto possibilidade de texto ou gênero de discurso:

Até um certo período da história do Ocidente, ele [o aluno] era formado para a literatura; hoje, ele é alfabetizado e preparado para entender textos, ainda orais ou já na forma escrita, como querem os PCNs, em que se educa para ler, não para a literatura. Assim, nem sempre a literatura se apresenta no horizonte do estudante, porque, de um lado, continua ainda sacralizada pelas instituições que a difundem, de outro, dilui-se no conceito vago de texto ou discurso (ZILBERMAN, 2007, p.265-266).

Zilberman afirma ainda que se antes, nos modelos escolares da Grécia Antiga, a literatura ficava no fim do processo de leitura, como uma meta de perfeição a ser atingida, já, nas escolas brasileiras, ela não está em parte alguma. Apesar de seu importante papel enquanto expressão plurissignificativa da linguagem capaz de humanizar e formar leitores críticos (CANDIDO, 2004), na escola, a literatura está relegada a um segundo plano, e parece não ter a importância que the é devida nas práticas de letramento. Os PCNs, com o objetivo de levar o estudante a ter domínio de uso da linguagem nos mais diversos gêneros orais e escritos, refletindo um trabalho pragmático com textos, fazem com que o livro literário fique 
à margem do processo de letramento, quando não está fora desse processo. A situação se agrava ainda mais quando se trata da literatura indígena: onde ela aparece na educação básica? Apenas nas comemorações do dia 19 de abril?

Se os PCNs sugerem que os gêneros devem ser trabalhados como objetos de ensino associados às diferentes práticas sociais, e se a linguagem é utilizada como mediadora dessas práticas, nas diversas representações do mundo feitas por meio dela, diferentes grupos sociais devem estar representados nos materiais didáticos usados para promover um ensino que realmente contribua para a plena e efetiva participação social do ser humano nessas práticas. A inserção das vozes tidas como minoritárias é fundamental para a inclusão social e para o desenvolvimento da competência discursiva do aluno na produção e recepção dos diversos discursos, especialmente o literário.

De qualquer forma, mesmo com uma dada interdição acerca do letramento literário nos PCNs, é verificável que esse importante processo tenha se fortalecido em algumas práticas escolares no presente século, conforme pontua a pesquisadora Graça Paulino:

Na escola ou fora dela, a experiência estética, na qual se inclui a leitura literária, compondo o letramento, 
esse processo ininterrupto e sempre imperfeito de formação de identidade, está sendo mais valorizada neste novo século, como modo de humanizar as relações enrijecidas pela absolutização de mercadorias (PAULINO, 2013, p.23).

No caso da produção de livros infantojuvenis voltados para a realidade indígena, espera-se que eles possam atuar no letramento literário de modo a revelar o encontro de identidades e a propiciar um olhar mais crítico do jovem leitor sobre a cultura tão diversa de seu país, um olhar que desvele o índio como um "ser" do presente, real, portador não só de diferenças, mas de igualdades. Tal comentário se faz pertinente, já que uma das consequências do processo de idealização e paralelo apagamento do índio na realidade social brasileira é a forma como os índios costumam ser representados nos livros didáticos. O verbo no pretérito imperfeito é uma constante, porque de forma geral os índios "eram", raramente eles "são". Costumamos ler nesses livros que os índios "moravam" em ocas, que o tacape "era" uma de suas armas de guerra. O pretérito imperfeito imprime a atmosfera mítica que, muitas vezes, ainda se constrói em torno do índio, apartando-o do momento presente, da realidade contemporânea da criança leitora do livro didático.

Diante disso, novas perspectivas de inserção da temática 
indígena na escola precisam ser refletidas, partilhando, por meio do letramento literário e da valorização da experiência estética - a que se refere Graça Paulino - na constituição da identidade leitora das crianças. Finalizando este trabalho, nos ateremos a discutir tal questão.

\section{LITERATURA INDÍGENA NAS PRODUÇÕES INFANTIS E JUVENIS: ATANDO IDEIAS}

Martins e Cosson (2008), ao discutirem a política da representação e a estética da identidade nas produções infantojuvenis, apresentam dois sentidos para o conceito de representação: o primeiro refere-se à noção de mimesis, e o segundo está ligado ao exercício do poder, quando a relação dos indivíduos com o Estado é mediada por alguma forma de representação. Para os autores, esses dois sentidos parecem fundir-se, especialmente quando relacionados às discussões étnico-raciais: as representações literárias, de qualquer ordem, são politicamente localizadas, e grupos tidos como minoritários, como indígenas e negros, por exemplo, recusam o estabelecido pelo outro e reivindicam a autoria na representação de sua identidade. Nesse sentido, a literatura desempenha papel importante, em especial a literatura infantil e juvenil, por sua contribuição na construção de tal identidade: 
[...] a questão da identidade é igualmente essencial para se compreender a discussão das abordagens sociais dos textos literários. [...] Além disso, uma das premissas do ensino da literatura é que por meio da leitura dos textos literários se promove e fortalece a identidade cultural dos alunos, sobretudo em termos de identidade nacional. Mais especificamente, a literatura estimula mecanismos de identificação positiva que podem ser usados para a ação política, ou seja, "para os membros de grupos historicamente oprimidos ou marginalizados", a literatura proporciona "a identificação com um grupo potencial e trabalha no sentido de fazer do grupo um grupo, mostrando-lhes quem ou que poderiam ser" (CULLER, 1999, p.113 apud MARTINS e COSSON, 2008, p.58).

Dessa forma, a literatura indígena surge como forma de superar o apagamento e como ponto de encontro entre a política da representação e a estética da identidade, sobretudo se direcionada às crianças, na formação de sua identidade leitora, dando a elas a possibilidade de revisitar a história e repensar valores, e aos personagens novos espaços, tempos e movimentações a partir de criações autóctones, "na denúncia dos preconceitos presentes em obras canonizadas e validação da produção contemporânea comprometida com a identidade positiva" (MARTINS e COSSON, 2008, p.59), 
sem perder de vista que esse ponto de encontro requer dos indivíduos e dos grupos o reconhecimento de si mesmos em suas igualdades e diferenças. Por fim, as palavras de Street (2007) vêm corroborar esse pensamento, ao revelar que diferentes práticas de letramento constituem a identidade e geram expectativas sociais acerca de comportamentos e papéis a desempenhar:

Diferentes letramentos, portanto, são associados a diferentes pessoalidades e identidades.[...]Quandofrequentamosum curso ou uma escola, ou nos envolvemos num novo quadro institucional de práticas de letramento, por meio do trabalho, do ativismo político, dos relacionamentos pessoais, etc., estamos fazendo mais do que simplesmente decodificar um manuscrito, produzir ensaios ou escrever com boa letra: estamos assumindo - ou recusando - as identidades associadas a essas práticas. A ideia de que as práticas de letramento são constitutivas de identidades fornece-nos uma base diferente - e eu argumentaria: mais construtiva - para compreender e comparar as práticas de letramento em diferentes culturas (STREET, 2007, p.470).

Pensar o letramento literário como uma fonte de experiência estética de humanização sob a perspectiva da pluralidade étnico-racial é pensar num ensino capaz de respeitar a diversidade da construção identitária do povo 
brasileiro, em toda sua alteridade. Disponibilizar espaços, tempo e condições para efetivar o letramento literário a partir da literatura indígena constitui um quadro de resistência, em meio a uma "selva urbana" onde o amor à Mãe Terra traduzse numa bela demonstração de humanidade, contribuindo para o verdadeiro exercício da cidadania.

\section{REFERÊNCIAS:}

Barthes, Roland (2007). Aula. São Paulo: Cultrix.

Borges, P. H. P. (2005). O movimento indígena no Brasil: histórico e desafios (Vol.88, n. 80, p. 42-48). São Paulo: Princípios.

Boudreau, D. (1993). Histoire de la littérature amérindienne au Québec. Montreal: I'Hexagone.

Brasil (1998). Secretaria de Educação Fundamental. Parâmetros Curriculares Nacionais - Língua Portuguesa. Brasília.

Candido, Antonio. (1999). Iniciação à Literatura Brasileira (3a ed). São Paulo: Humanitas/ FFLCH/USP. . (2004). Vários escritos (4a ed.). Rio de Janeiro: Ouro sobre Azul.

Cardoso, R. E. (2011). A recente literatura indígena: a história que não nos contaram. Trabalho de Conclusão de Curso Universidade Federal do Rio Grande do Sul (Licenciatura em Letras). In http://hdl.handle. net/10183/40393. Acesso em dezembro/ 2014.

Funari, P. P. \& Piñon, A. (2014). A temática indígena na escola. São Paulo: Contexto. Graúna, Graça. (2013). Contrapontos da literatura indígena contemporânea no Brasil. Belo Horizonte: Mazza Edições.

Lajolo, M.; Zilberman, R. (1993). Um Brasil para crianças - para conhecer a literatura infantil brasileira: histórias, autores e textos (4a ed.). São Paulo: Global. Martha, A. A. P. (2012). Autoria indígena na produção infantojuvenil contemporânea. In: Anais do Seminário Internacional de História da 
Literatura (Vol. 1, p. 324-334). In http://ebooks.pucrs.br/edipucrs/Ebooks/ Web/978-85-397-0198-/Trabalhos/3.pdf. Acesso em julho/ 2014. Martins, A. \& Cosson, R. (2008). Representação e identidade: política e estética étnico-racial na literatura infantil e juvenil. In: Paiva, A. \& Soares, M. (Org.) Literatura infantil: políticas e concepções (p. 53-78). Belo Horizonte: Autêntica.

Paulino, Graça. (2013). Formação de leitores: a questão dos cânones literários. In: Gama-Khalil, Marisa Martins; Andrade, Paulo Fonseca. As literaturas infantil e juvenil... ainda uma vez. Uberlândia: GPEA; CAPES.

Ribeiro, D. (1995). O povo brasileiro: a formação e o sentido do Brasil (2a ed.). São Paulo: Companhia das Letras.

Sarlo, Beatriz. (2005). Paisagens imaginárias. São Paulo: Editora da Universidade de São Paulo.

Street, Brian. (2007). Perspectivas interculturais sobre o letramento (n.8, p. 465488). Revista de Filologia e Linguística Portuguesa da Universidade de São Paulo. Thiél, J. (2014). Uma literatura em ascensão. Revista Carta Fundamental (n. 58, p. 8-11). Zilberman, R. (2007). Letramento literário: não ao texto, sim ao livro. In Literatura e letramento: espaços, suportes e interfaces - $O$ jogo do livro (p. 245-266). BeloHorizonte: Autêntica/CEALE/FaE/UFMG.

Marisa Martins Gama-Khalil tem pós-doutorado pela Universidade de Coimbra (2014), é professora associada da Universidade Federal de Uberlândia. Líder do Grupo de Pesquisas em Espacialidades Artísticas GPEA/CNPq. É pesquisadora contemplada com a bolsa de Produtividade em Pesquisa do CNPq. Contato: mmgama@gmail.com

Lorena Faria de Souza é mestranda do Curso de Mestrado Profissional em Letras da Universidade Federal de Uberlândia - PROFLETRAS/UFU. Membro do Grupo de Pesquisas em Espacialidades Artísticas - GPEA/ CNPq. Professora efetiva da rede pública federal de ensino. Contato: lorenarevisao@yahoo.com.br 